\title{
Immunohistochemical detection of DNA topoisomerase I in formalin fixed, paraffin wax embedded normal tissues and in ovarian carcinomas
}

\author{
Joseph A Holden, Mark P Rahn, Christopher J Jolles, Sergey V Vorobyev, Igor B Bronstein
}

Department of Pathology, University of Utah Health Sciences Center, Salt Lake City, Utah, 84132, USA

J A Holden

M P Rahn

Special Gynecology and Oncology, 508 East South Temple, Suite 205, Salt Lake City, Utah, 84102, USA

C J Jolles

\section{Albert Einstein College of Medicine, Department of Biochemistry, 1300 Morris Park Avenue, Bronx, New York, 10161, USA $S$ V Vorobyev}

Engelhardt Institute of Molecular Biology,

Russian Academy of Sciences, Moscow, Russia

I B Bronstein

Correspondence to: Dr Holden.

Accepted for publication 3 July 1997

\begin{abstract}
Aims-To determine, by in situ immunohistochemistry, whether ovarian carcinomas have increased expression of DNA topoisomerase I.

Methods-Paraffin wax blocks obtained from 15 samples of normal human tissues and from 14 cases of ovarian cancer were cut on to glass slides and immunohistochemically stained for topoisomerase I. The primary antibody was a mouse monoclonal that recognises topoisomerase $I$ in western blots. Colour was detected using a peroxidase system with diaminobenzidine as the chromogen. The expression of topoisomerase $I$ in the tissues and tumours was graded subjectively from 0 to $3+$ based on the colour intensity of the immunostain.
\end{abstract}

Results-In normal tissues, topoisomerase I expression was strongest in the mucosal lymphocytes in the gastrointestinal tract and in the germinal centres of the tonsil. Weak topoisomerase I staining was found in the columnar epithelium of the gastrointestinal tract and in squamous mucosa. In the series of ovarian carcinomas, raised topoisomerase I was observed in $43 \%$ (6 of 14) of the tumours. Of the tumours with raised topoisomerase I, only three contained a population of rapidly cycling cells. Therefore, $21 \%$ of our series of ovarian carcinomas ( 3 of 14 ) had raised topoisomerase I expression and were proliferating rapidly.

Conclusions-Topoisomerase I expression in formalin fixed, paraffin wax embedded human tissues can be evaluated by immunohistochemical staining. Increases in topoisomerase I occur in some cases of ovarian cancer.

(F Clin Pathol: Mol Pathol 1997;50:247-253)

Keywords: DNA topoisomerase I; ovarian carcinoma; immunohistochemistry

DNA topoisomerase I is an important enzyme in a number of cellular processes. During catalysis, the enzyme makes a transient single strand DNA break, which is then re-ligated at the end of the reaction. This mechanism of action enables the enzyme to carry out in vitro topoisomerisations such as the relaxation of supercoiled plasmid DNA. ${ }^{1}$ The enzyme's best characterised physiological role is in transcription, where it has been shown that topoisomerase $I$ is located in regions of the genome that are undergoing active RNA synthesis. ${ }^{2-4}$ It is likely that in these areas, the enzyme removes superhelical stress in the DNA, thereby enabling RNA polymerase to function properly. Recently, data have suggested that, in addition, the enzyme may play a role in the initiation of transcription. ${ }^{56}$

Apart from these basic biological functions, topoisomerase I has generated extensive clinical interest because it has been shown to be the sole molecular target of the camptothecin group of anticancer drugs. ${ }^{78}$ Many of these drugs are now undergoing clinical trials and are showing activity against a wide array of solid human neoplasms. ${ }^{9-11}$ All of these drugs stabilise topoisomerase $I$ in the act of cutting DNA. The stabilised complex consists of a transient single strand DNA break which is covalently bound to the enzyme via a 3 phosphoryl group on the DNA to tyrosine 723 of topoisomerase $\mathrm{I}^{12}{ }^{13}$ This complex is referred to as a cleavable complex and is lethal to cells. ${ }^{14}$ The lethality of the cleavable complex may be due to its interaction with the replication fork resulting in damaged DNA and cell death. This interpretation is consistent with both the $S$ phase specificity of the drugs and the fact that inhibition of DNA polymerase activity protects cells from camptothecin toxicity. ${ }^{15} 16$

As predicted from the above model, results from several experimental systems indicate that the sensitivity of cells to topoisomerase I targeted drugs is dependent on quantitative amounts of topoisomerase I. The more topoisomerase I a cell has, the more cleavable complexes can be formed in response to topoisomerase I targeted drugs, and the more drug sensitive the cell is. ${ }^{817}$ Resistance to camptothecin has also been associated with mutations in the topoisomerase I protein, strengthening further the correlation between these drugs and topoisomerase $\mathrm{I}^{18-21}$ These data led to the hypothesis that the response of patients to topoisomerase I targeted drugs might depend on tumour topoisomerase I concentrations. It is known that topoisomerase I concentrations vary widely in human cancers. ${ }^{22-24}$ Unfortunately, clinical responses to topoisomerase I drugs have not been correlated with tumour topoisomerase I concentrations. 
One of the reasons that tumour topoisomerase I concentrations have not been correlated with patient response to topoisomerase I drug therapy is because of the difficulties encountered when measuring topoisomerase I cleavable complexes, topoisomerase I catalytic activity, and topoisomerase I immunoprotein concentrations in fresh tumour tissue. Tumour tissue samples are heterogeneous and contain different amounts of normal stromal and inflammatory cells as well as large areas of necrosis. In addition, many samples provide only enough tissue for diagnosis and little is left for biochemical measurements. Because of these problems, we sought to develop an immunohistochemical stain that could be used to estimate topoisomerase I activity in routinely processed human tissue samples. In this report we show that a previously described mouse monoclonal antibody, which is specific for mammalian topoisomerase $\mathrm{I}^{24}$ is capable of recognising topoisomerase $I$ in paraffin wax embedded, formalin fixed human tissue sections. We used this antibody to determine relative amounts of topoisomerase $I$ in several normal human tissues and in a series of 14 ovarian carcinomas.

\section{Materials and methods}

CHEMICALS AND BIOLOGICAL REAGENTS

The sources of these were as previously described. ${ }^{25}$

\section{SOURCES OF TISSUE}

Normal and malignant human tissues for topoisomerase I immunostaining were obtained from routine specimens evaluated by the Division of Surgical Pathology at the University of Utah Health Sciences Centre. The characteristics of the ovarian carcinomas used in this study have been described. ${ }^{26}$ The use of human tissue for this work was approved by the Institutional Review Board at the University of Utah.

\section{PREPARATION OF DNA TOPOISOMERASE I}

ANTIBODIES

A mouse monoclonal antibody directed against mammalian topoisomerase I was developed as described previously. ${ }^{24}$ Briefly, this antibody was raised against purified calf thymus topoisomerase I in BALB/c mice. Mouse splenocytes were fused with the mouse myeloma cell line SP2/0-AG-14 and hybridomas were screened for the production of antitopoisomerase I antibodies using purified calf thymus topoisomerase I immobilised on to plastic wells. Positive clones were subcloned twice by limiting dilution and were used to prepare ascitic fluid by peritoneal injection into primed BALB/c mice.

Crude hybridoma supernatant containing topoisomerase I antibody can be used undiluted for immunostaining and at a 1/100 dilution for western blotting. To obtain a more concentrated antibody solution, the topoisomerase I antibody can be purified from the hybridoma supernatant by chromatography over protein G (Pharmacia, Piscataway, New Jersey, USA) in procedures identical to those described previously for the purification of antibodies against DNA topoisomerase $\mathrm{II} .^{25}$ The purified topoisomerase I antibody can be used in immunostaining at a dilution of $1 / 200$ $1 / 400$ and in western blots at a dilution of $>$ $1 / 1000-1 / 2000$.

IMMUNOHISTOCHEMICAL STAINING FOR DNA TOPOISOMERASE I

For staining of topoisomerase $I$ in formalin fixed, paraffin embedded tissues, samples were $\overline{\bar{O}}$ cut into $3 \mu \mathrm{m}$ sections and applied to Super- $\frac{\vec{D}}{\widehat{D}}$ frost Plus slides (Baxter Diagnostics Inc, $\stackrel{\square}{\Omega}$ McGaw Park, Illinois, USA). The slides were के deparaffinised as described for staining the $\vec{O}$ related enzyme, topoisomerase II. ${ }^{25}$ Following $\vec{\overrightarrow{ }}$ deparaffinisation, the slides were incubated in $\omega$ $10 \mathrm{mM}$ sodium citrate ( $\mathrm{pH} 6.0$ ), placed in a 3 pressure cooker (Nordicware, Minneapolis, Minnesota, USA) and heated for 27 minutes on high in a Samsung microwave oven. After i cooling at room temperature for 30 minutes, the slides were washed twice with water. 을 Topoisomerase I immunostaining was then $\vec{O}$ carried out with the use of a Ventana 320 automated immunohistochemical stainer (Ventana $\stackrel{\circ}{\circ}$ Medical Systems, Tucson, Arizona, USA) in $\stackrel{\Phi}{=}$ accordance with the manufacturer's instruc- $\vec{\theta}$ tions. Following incubation with the topoisomerase I antibody, detection was accomplished by a subsequent incubation with a secondary antimouse IgG linked to biotin, fol- $\bar{\partial}$ lowed by incubation with streptavidin linked to horseradish peroxidase. Colour development $\stackrel{\mathbb{Q}}{\varrho}$ was performed using diaminobenzidine as the $\overrightarrow{\overrightarrow{0}}$ chromogen. Negative controls consisted of 3 omitting the primary antibody during the immunostaining procedure.

Topoisomerase I is not a cell cycle specific protein and all cells need the enzyme for $:$ synthesis of RNA. ${ }^{27-29}$ Therefore, in order to determine the relative expression of the enzyme of between different tissue and tumour types, the antibody needs to be titrated so that normal 음 tissues will be negative in an immunostain. $?$ Increased enzyme expression can be observed by comparison to this negative control. For a $N$ negative control, we chose to dilute the $N$ antibody such that a slide of normal liver or $N$ normal testis is negative in the topoisomerase $I_{\sigma}^{\omega}$ stain but an ovarian cancer with demonstrated high levels of topoisomerase $\mathrm{I}^{24}$ is positive. The $\frac{\mathbb{D}}{\mathscr{T}}$ strong staining in the ovarian cancer was set at $\stackrel{\mathcal{\infty}}{+}$ $3+$ and the evaluation of the topoisomerase $I \frac{T}{T}$ stain then becomes a subjective grading of the $\frac{\vec{D}}{\vec{D}}$ stain on a scale of 0 to $3+$. Grading was as fol- $\frac{?}{1}$ lows: 0 , no detectable staining; $1+$, faint $\stackrel{\mathbb{Q}}{\varrho}$ nuclear staining; $2+$, easily visible nuclear staining; $3+$, intense nuclear staining.

After tissue sections were cut on to Superfrost Plus slides, topoisomerase I was stillō

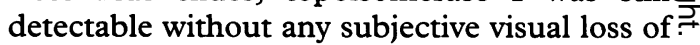
staining intensity for at least six months.

WESTERN BLOTTING

The procedures for western blotting have been described in detail in elsewhere. ${ }^{24} 25$ 

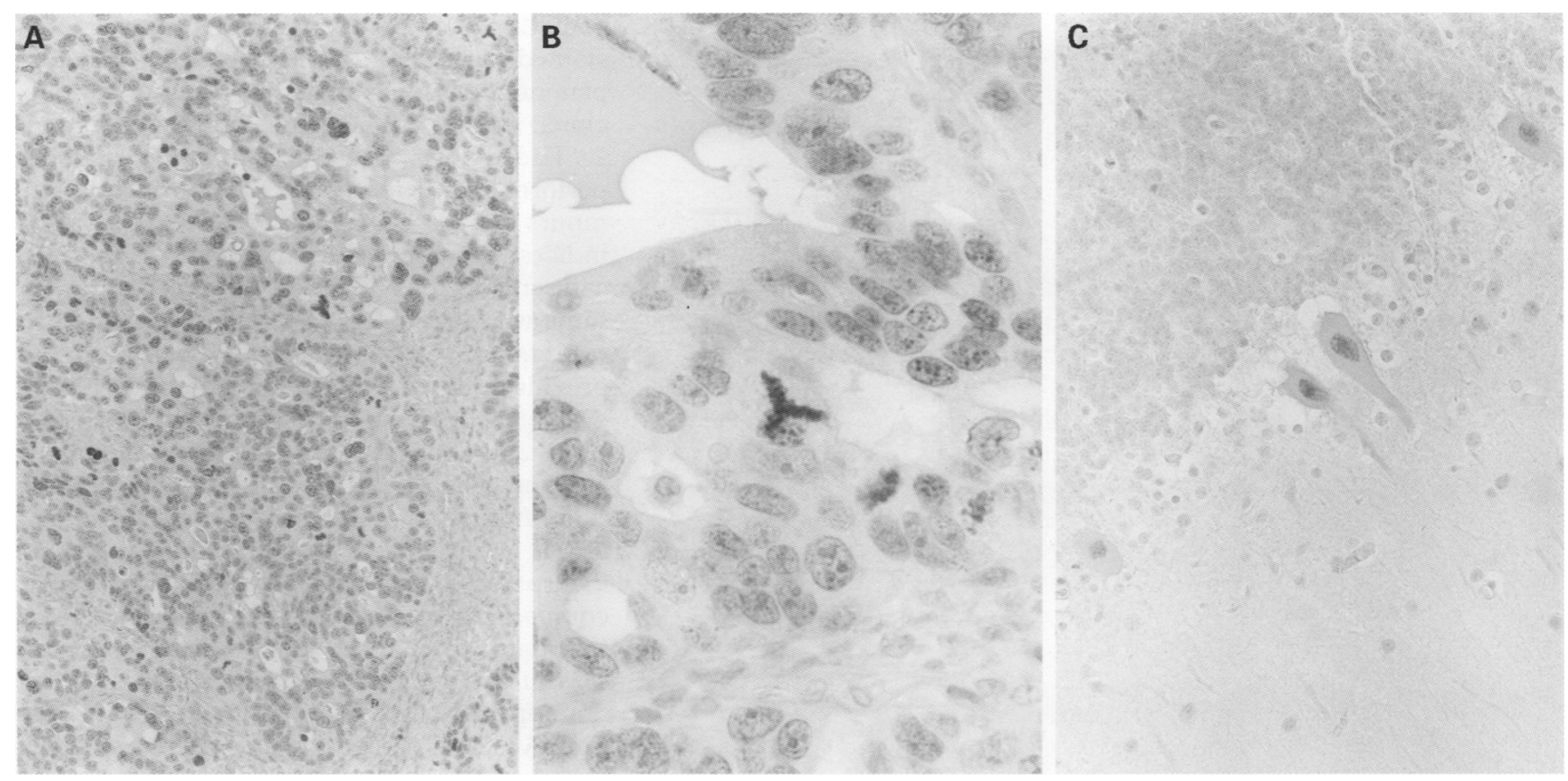

Figure 1 Immunohistochemical staining of DNA topoisomerase I in paraffin wax embedded, formalin fixed human tissues. (A) An ovarian carcinoma that has been shown to contain raised topoisomerase I immunoprotein and catalytic activity, ${ }^{24}$ was immunohistochemically stained with a monoclonal antibody specific for mammalian topoisomerase I. The tumour cell nuclei stain positively and the surrounding fibrous stroma is negative $(\times 100)$. (B) High power magnification $(\times 400)$ of the topoisomerase I staining in the ovarian carcinoma shows a diffuse punctate stain throughout the nucleus of the tumour cells. Mitotic figures are strongly positive. (C) Topoisomerase I immunostaining of normal cerebellum is localised to the Purkinje cells $(\times 400)$.

\section{Results}

IMMUNOHISTOCHEMICAL STAINING

The mouse monoclonal antibody against topoisomerase I recognised the enzyme in paraffin embedded, formalin fixed human tissue sections. Immunohistochemical staining of a high grade ovarian carcinoma with a mouse monoclonal antibody directed against topoisomerase I is shown in fig 1A. Most cells show positive nuclear staining. Mitotic figures stain strongly (fig 1B). No staining of the surrounding fibrous tissue is noted. This particular ovarian carcinoma had previously been shown to contain high levels of DNA topoisomerase I catalytic activity. ${ }^{24}$ In addition, western blots of extracts prepared from this tumour with the same antibody used in the immunostain, demonstrate abundant topoisomerase I immunoprotein. ${ }^{24}$ This previous data confirm the specificity of the antibody and indicate that the staining observed in the ovarian carcinoma is due to the presence of topoisomerase $I$. Because this particular tumour has been biochemically characterised with respect to topoisomerase I catalytic activity and immunoprotein, it was used as a positive control for topoisomerase I immunostaining. The intensity of the stain was set at $3+$

\section{IMMUNOHISTOCHEMICAL STAINING OF NORMAL} TISSUES FOR TOPOISOMERASE I

Although all normal tissues and organs contain topoisomerase I enzymatic activity, enzyme levels are not always high enough for topoisomerase I protein to be detected on western blots. ${ }^{24}$ This suggests that most normal tissues may not show a positive result in a topoisomerase I immunostain even though they contain topoisomerase I. This is confirmed in table 1, which demonstrates that most normal tissues studied are negative for topoisomerase I at the
Table 1 Topoisomerase I distribution in several normal tissues and organs

\begin{tabular}{ll}
\hline Site & Expression \\
\hline Squamous epithelium & $0-1+$ \\
Blood vessels & 0 \\
Smooth muscle & 0 \\
Breast & 0 \\
Ovary & 0 \\
Fallopian tube & 0 \\
Liver & 0 \\
Cerebellum & $2+$ (Purkinje cells) \\
Colon & $1+$ (glandular epithelium) \\
& $2+$ (mucosal lymphocytes) \\
Salivary gland & 0 \\
Pancreas & 0 \\
Prostate & 0 \\
Seminal vesicle & 0 \\
Tonsil & $2+$ (germinal centres) \\
Testis & 0
\end{tabular}

Expression was estimated as described in materials and methods. A value of 0 means the antigen is not detected under the staining conditions used. All normal cells most likely contain topoisomerase I. ${ }^{24}$

dilution of antibody used in the immunostaining. Of the 15 normal tissues and organs studies, topoisomerase I positivity is only detected in the germinal centres of the tonsil, glandular epithelium, and mucosal lymphocytes of the colon, keratinocytes of squamous epithelium, and in the Purkinje cells of the cerebellum. The topoisomerase I immunostain of cerebellum is shown in fig 1C. For the testis, the lack of detectable topoisomerase I immunostaining is confirmed by the absence of detectable topoisomerase I protein by western blotting (fig 2).

\section{TOPOISOMERASE I IMMUNOSTAINING OF OVARIAN} CARCINOMAS

Because the highest concentrations of topoisomerase I previously observed in a group of carcinomas were in tumours of ovarian origin, ${ }^{24}$ and because topoisomerase I targeted drugs are showing promising preclinical ${ }^{31}$ and clinical, ${ }^{11}$ 


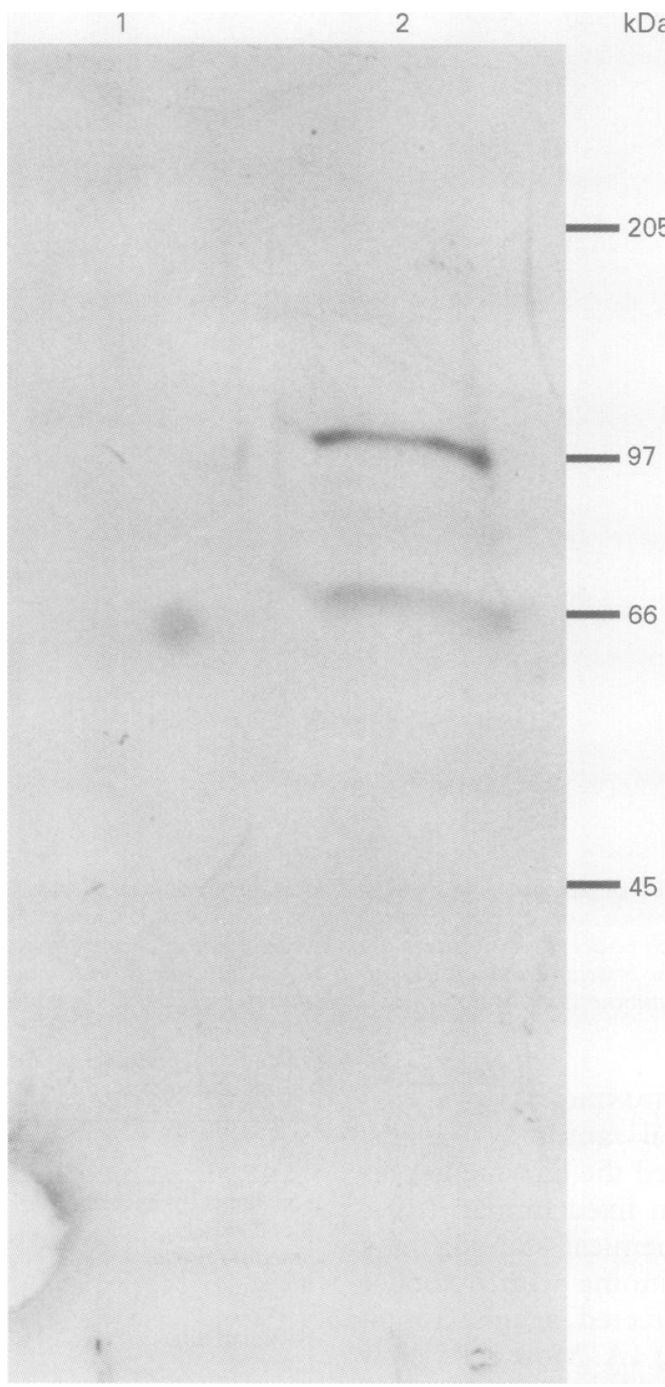

Figure 2 Western blot of normal testis for topoisomerase I. Nuclear extracts prepared from normal human testis and from splenic tissue which was diffusely infiltrated by non-Hodgkin's lymphoma were subjected to western blot analysis. The lymphoma has previously been shown to contain increased amounts of topoisomerase $I .^{30}$ Each lane contained $5 \mu \mathrm{g}$ of nuclear extract protein. The antibody used for detection was the same antibody used in the immunostaining and was diluted 1/200. Detection was with an alkaline phosphatase system. Lane 1: no detectable topoisomerase I immunoprotein is observed in nuclear extracts prepared from normal testis. This confirms the immunostaining result in table 1. Lane 2: easily detectable topoisomerase I immunoprotein is seen in nuclear extracts prepared from non-Hodgkin's lymphoma tissue. The two protein species seen on the gel at $100 \mathrm{kDa}$ and $66 \mathrm{kDa}$ represent the intact and the common proteolytic breakdown fragment of topoisomerase I, respectively. ${ }^{24}$

Table 2 Topoisomerase I expression in primary and metastatic ovarian carcinomas

\begin{tabular}{lllll}
\hline Patient & Site & Grade & Topo I* & Topo II at \\
\hline 1 & Ovary & III & $2+$ & 40.0 \\
2 & Omentum (metastatic) & III & $3+$ & 37.5 \\
3 & Ovary & III & $3+$ & 70.5 \\
4 & Omentum (metastatic) & III & $2+$ & 52.5 \\
5 & Colon (metastatic) & II & $2+$ & 51.5 \\
6 & Omentum (metastatic) & III & $0-1+$ & 40.5 \\
7 & Omentum (metastatic) & III & 0 & 54.5 \\
8 & Ovary & II & $1+$ & 20.5 \\
9 & Ovary & I & $2+$ & 25.5 \\
10 & Omentum (metastatic) & III & $1+$ & 83.5 \\
11 & Ovary & III & $1+$ & 52.5 \\
12 & Omentum (metastatic) & III & $1+$ & 22.5 \\
13 & Omentum (metastatic) & III & 0 & 67.5 \\
14 & Omentum (metastatic) & II & 0 & 14.0 \\
\hline
\end{tabular}

${ }^{\star}$ Expression is estimated as described in materials and methods. †Indices were determined as described. ${ }^{26}$ activity against ovarian cancer, we immunostained samples of ovarian carcinoma from 14 patients for topoisomerase I using our monoclonal antibody. The results are shown in table 2. The topoisomerase II $\alpha$ indices had been performed previously on these particular tu-으 mours and were found to correlate with MIB1 0 indices. ${ }^{26}$ This indicates that topoisomerase II $\alpha \stackrel{\text { F }}{5}$ can serve as a proliferation marker in much the $\vec{\Rightarrow}$ same way that MIB1 has done. Therefore, the $\stackrel{\vec{\rho}}{\rightarrow}$ expression of topoisomerase II $\alpha$ in a tumour? provides information about the number of $\frac{\bar{D}}{\bar{n}}$ cycling cells. Each topoisomerase II $\alpha$ index $\overrightarrow{\widehat{\sigma}}$ represents the number of positive staining $\cong$ tumour cells divided by the total number of is tumour cells counted, $\times 100$. The topoisomer- $\overrightarrow{0}$ ase II $\alpha$ indices of the ovarian cancers are $\overrightarrow{-}$ incorporated into table 2 solely for ease of $\vec{\omega}$ comparison with the topoisomerase I expres- $\bar{\exists}$ sion data. Clearly, the topoisomerase I expres-? sion in this group of ovarian carcinomas does. not appear to be correlated with cell prolifera-iv tion. A lack of close correlation between topoi- $\_$ somerase I and cell proliferation has previouslyo been suggested. ${ }^{24}{ }^{32}$

An example of a carcinoma with $3+O$ topoisomerase I staining is shown in fig $3 \mathrm{~A}$ and $\stackrel{\circ}{\circ}$ a carcinoma with $2+$ topoisomerase I staining is shown in fig 3B. Approximately $43 \%$ of the ovarian carcinomas $(6 / 14)$ have strong topoi- 6 somerase I expression (2-3+).

\section{Discussion}

DNA topoisomerase I has been shown clearlyō to be the target of the camptothecin group of anticancer drugs. The sensitivity of cells to 0 these drugs is dependent on the concentration $\overrightarrow{\vec{B}}$ of topoisomerase I. Cells with high topoisomerase I concentrations are sensitive to these agents and cells with low topoisomerase I concentrations are resistant. ${ }^{8}{ }^{17}$ This has stimulated $\overline{0}$ much research into estimating topoisomerase I: concentrations in human malignancies and from these studies it has been found that someô types of human cancers have raised concentrations of topoisomerase I. ${ }^{22-24}$ However, meas-윽 urements used in this work, such as measuring topoisomerase I catalytic activity and immunoprotein, are cumbersome and require fresh tumour tissue and sophisticated laboratory techniques. In addition, these techniques cannot distinguish between topoisomerase $\mathrm{I}^{\mathrm{\omega}}$ from normal or neoplastic cells. This is especially problematical in biopsy material? from patients, which generally contain a黑 mixture of neoplastic and normal cells.

In this report, we demonstrate that it is now possible to estimate relative topoisomerase $I_{\stackrel{Q}{\mathbb{Q}}}$ concentrations in paraffin embedded, formalin $\frac{\vec{Q}}{\stackrel{Q}{Q}}$ fixed human tissues. With this method, we were able to screen several normal tissues as well as malignant tissues for topoisomerase I. WeO found that in normal tissues, the strongest staining is in lymphocytes such as those found을 in the gastrointestinal tract. The germinal centres of the tonsil were also positive. These cells might be expected to be undergoing active transcription during the synthesis of antibody, which might explain the easily detected topoisomerase I. Topoisomerase I has been localised 

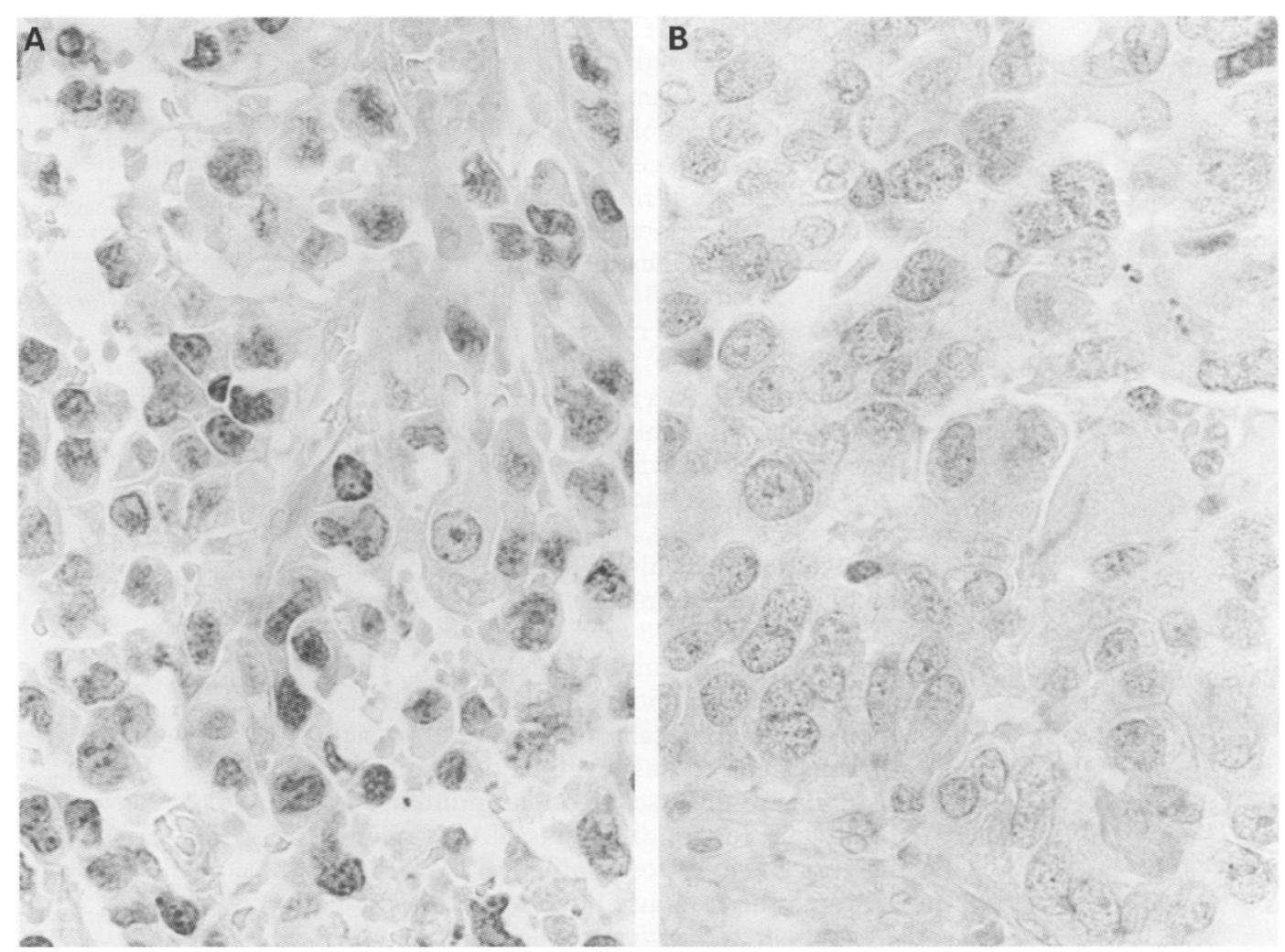

Figure 3 Variation of topoisomerase I staining intensity in ovarian carcinomas. (A) Topoisomerase I staining in an ovarian carcinoma. The enzyme shows a nuclear localisation and the intensity of the stain was subjectively graded as equal to the intensity of the positive control shown in fig $1 A$ and $B$. Therefore, the topoisomerase I staining intensity was graded as $3+(\times 400)$. (B) Topoisomerase I staining in an ovarian carcinoma shows a nuclear localisation and the intensity of the stain was subjectively graded as less intense than the positive control shown in fig $1 A$ and $B$. Therefore, this tumour was graded as $2+$ for topoisomerase $I(\times 400)$.

in areas of active transcription. ${ }^{2-4}$ However, in normal tissues, the enzyme is clearly not associated with cell proliferation. This is easily seen in squamous epithelium as well as colonic mucosa, both of which show a weak staining in all of the epithelial cells. The proliferating cells in these tissues have been localised to the basal layer of the squamous epithelium and the crypts of the colon by immunohistochemical staining for topoisomerase II, a marker of cell proliferation. ${ }^{33}$ The staining of the Purkinje cells of the cerebellum.is interesting and suggests further study.

Topoisomerase I expression in ovarian carcinoma varies from weak to strong. The molecular mechanism to explain the rise in topoisomerase I concentrations in some of these neoplasms remains undetermined but studies from cultured cells suggest it could be a result of increased topoisomerase I gene transcription, ${ }^{34}$ or amplification of the topoisomerase I gene. ${ }^{35}$ Our data also show that, at least in the small sample of tumours that we evaluated, there is no apparent correlation with proliferation or grade. This lack of a correlation between topoisomerase I and proliferation has been reported by others, ${ }^{24}{ }^{32}$ and may have important clinical implications. Clearly, topoisomerase I targeted drugs are most effective during $S$ phase because it is believed that the DNA break stabilised by the drugs is converted into a lethal lesion by interaction with the replication fork. ${ }^{16}$ Therefore, it is possible that the only tumours that could be treated effectively with topoisomerase I agents are those that contain raised levels of topoisomerase $I$ and, in addition, have a large population of cycling cells. A recent study on the camptothecin sensitivity of human lymphocytes suggests that this hypothesis may be true. ${ }^{36}$

Because topoisomerase II $\alpha$ has been demonstrated recently to be a proliferation marker that can be used on paraffin embedded, formalin fixed human tissues, ${ }^{2633} 37$ it can be used to estimate the number of cycling cells in a tumour. If we assume arbitrarily that a topoisomerase II $\alpha$ index of 50 or greater identifies a rapidly cycling tumour $50 \%$ of the cells in $G_{2}, S$, or $M$ phase), then by inspection of table 2 , only three of the 14 patients we studied (21\%) had raised topoisomerase I activity in tumours that were proliferating rapidly. Interestingly, it has been reported recently that $16.3 \%$ of patients with ovarian carcinoma show a response to topotecan. ${ }^{11}$ Unfortunately, topoisomerase I levels and cell proliferation data were not obtained for these patients.

Surprisingly, we found that mitotic figures stained strongly positive for topoisomerase I. In general, topoisomerase I has not been thought of as an enzyme necessary for the condensation and subsequent separation of chromosomes. These functions have been attributed to the related enzyme, DNA topoisomerase II..$^{38-40}$ However, the topoisomerase I staining intensity on mitotic figures is as strong as that seen for topoisomerase II (Holden, unpublished data, 1997) and might suggest that topoisomerase I also plays an important role in chromosome structure and function. Indeed, recent evidence in yeast indicates that there are several factors that appear to interact with topoisomerase I to allow for proper mitotic 
chromosome structure. These TRF (DNA topoisomerase I related function) genes have been found to have human homologues, ${ }^{41}$ and might suggest that topoisomerase I performs a similar role in human cells.

The predominantly nuclear localisation observed in our immunostaining is of interest because previous studies have indicated a predominantly nucleolar localisation of topoisomerase. ${ }^{42}$ However, recently, in work with cultured cells, it has been shown that the enzyme can shift from a predominantly nucleolar localisation to a nuclear localisation depending on the growth conditions. ${ }^{4344}$ Our series of ovarian carcinomas showed mostly a nuclear stain. However, in agreement with previous data, we have also observed nucleolar localisation of topoisomerase I. This was identified in a squamous cell carcinoma of the head and neck (Holden, unpublished data). The potential clinical significance of this difference in topoisomerase I localisation, as well as the mechanism involved has yet to be determined.

In summary, the use of an immunohistochemical stain for topoisomerase I may allow for the correlation of topoisomerase I concentrations with the response of patients to topoisomerase I targeted anticancer agents. In addition, screening of various classes of human malignancies for topoisomerase I expression can now be rapidly performed and may identify groups of tumours potentially treatable and curable with drugs that target the enzyme.

This work was funded by a research educational grant from Upjohn-Pharmacia. We thank J Chris Pitchford for his interest in the topoisomerases as anticancer drug targets.

1 Wang JC. DNA topoisomerases. Annu Rev Biochem 1996;65:635-92.

2 Gilmour DS, Pflugfelder G, Wang JC, Lis JT. Topoisomerase I interacts with transcribed regions in drosophila cells. Cell 1986;44:401-7.

3 Elgin SCR, Gilmour DS. Localization of specific topoisomerase I interactions within the transcribed region of active heat shock genes by using the inhibitor camptothecin. Mol Cell Biol 1987;7:141-8.

4 Stewart AF, Schutz G. Camptothecin-induced in vivo topoisomerase I cleavages in the transcriptionally active tyrosine aminotransferase gene. Cell 1987;50:1109-17.

5 Kretzschmar M, Meisterernst M, Roeder RG. Identification of human DNA topoisomerase I as a cofactor for activatordependent transcription by RNA polymerase II. Proc Natl Acad Sci USA 1993;90:11508-12.

6 Merino A, Madden KR, Lane WS, Champoux JJ, Reinberg D. DNA topoisomerase $I$ is involved in both repression and activation of transcription. Nature 1993;365:227-32.

7 Eng W, Faucette L, Johnson RK, Sternglanz R. Evidence that DNA topoisomerase I is necessary for the cytotoxic effects of camptothecin. Mol Pharm 1989;34:755-60.

8 Bjornsti MA, Benedetti P, Viglianti GA, Wang JC. Expression of human DNA topoisomerase I in yeast cells lacking yeast DNA topoisomerase I: restoration of sensitivity of the cells to the antitumour drug camptothecin. Cancer Res 1989;49:6318-23.

9 Verschraegen CF, Levy T, Kudelka AP, Llerena E, Ende K, Freedman RS, et al. Phase II study of irinotecan in prior chemotherapy-treated squamous cell carcinoma of the cerchemotherapy-treated squamous
vix. $\mathcal{F}$ Clin Oncol 1997;15:625-31.

10 Conti JA, Kemeny NE, Saltz LB, Huang Y, Tong WP, Chao $\mathrm{T}$, et al. Irinotecan is an active agent in untreated patients with metastatic colorectal cancer. $\mathcal{F}$ Clin Oncol 1996;14: 709-15

11 Creemers GJ, Bolis G, Scarfone G, Lacave AJ, Guastalla JP, Despax $\mathrm{R}$, et al. Topotecan, an active drug in the second-line treatment of epithelial ovarian cancer: results of a large European phase II study. $\mathcal{f}$ Clin Oncol 1996;14:3056-61.

12 Eng W, Pandit SD, Sternglanz R. Mapping of the active site tyrosine of eukaryotic DNA topoisomerase I. $f$ Biol Chem tyrosine of eukaryotic

13 Fujimori A, Harker WG, Kohlhagen G, Hoki Y, Pommier Y. Mutation at the catalytic site of topoisomerase I in
CEM/C2, a human leukemia cell line resistant to CEM/C2, a human leukemia cell line camptothecin. Cancer Res 1995;55:1339-46.
14 Hsiang Y, Hertzberg R, Hecht S, Liu LF. Campthothecin induces protein-linked DNA breaks via mammalian DNA topoisomerase I. $\mathcal{F}$ Biol Chem 1985;260:14873-8.

15 Hsiang Y, Lihou MG, Liu LF. Arrest of replication forks by drug-stabilised topoisomerase I-DNA cleavable complexes as a mechanism of cell killing by camptothecin. Cancer Res 1989;49:5077-5082.

16 Nitiss JL, Wang JC. Mechanisms of cell killing by drugs that trap covalent complexes between DNA topoisomerases and DNA. Mol Pharmacol 1996;50:1095-102.

17 Madden KR, Champoux JJ. Overexpression of human topoisomerase I in baby hamster kidney cells: hypersensi- ? tivity of clonal isolates to camptothecin. Cancer Res 1992;52:525-32.

18 Tamura H, Kohchi C, Yamada R, Ikeda T, Koiwai O, Petterson E, et al. Molecular cloning of a cDNA of a camptothecin-resistant human DNA topoisomerase I and $\overline{\underline{\sigma}}$ identification of mutation sites. Nucleic Acids Res 1991;19: $\overline{\bar{S}}$ 69-75.

19 Tanizawa A, Bertrand R, Kohlhagen G, Tabuchi A, Jenkins $\stackrel{\mathbb{Q}}{\Omega}$ J, Pommier Y. Cloning of chinese hamster DNA topoisomerase I cDNA and identification of a single point muta- $\omega$ tion reponsible for camptothecin resistance. $\mathcal{F} \mathrm{Biol}$ Chem $\vec{\circ}$ 1993;268:25463-8

20 Benedetti P, Fiorani P, Capuani L, Wang JC. Camptothecin resistance from a single mutation changing glycine 363 of $\omega$ human DNA topoisomerase I to cysteine. Cancer Res 1993; 53:4343-8.

21 Rubin E, Pantazis P, Bharti A, Toppmeyer D, Biovanella B, Kufe D. Identification of a mutant human topoisomerase IG with intact catalytic activity and resistance to 9-nitrocamptothecin. F Biol Chem 1994;269:2433-9.

22 Husain I, Mohler JL, Seigler HF, Besterman JM. Elevation is of topoisomerase I messenger RNA, protein, and catalytic activity in human tumours: demonstration of tumour-type $\mathrm{O}$ specificity and implications for cancer chemotherapy. Cancer Res 1994;54:539-46.

23 McLeod HL, Douglas F, Oates M, Symonds RP, Prakash D, van der Zee AGJ, et al. Topoisomerase I and II activity in human breast, cervix, lung, and colon cancer. Int $\mathcal{f}$ Cancer $O$ 1994;59:607-11.

24 Bronstein IB, Vorobyev S, Timofeev A, Jolles CJ, Alder SL, Ф Holden JA. Elevations of DNA topoisomerase I catalytic $\overrightarrow{0}$ activity and immunoprotein in human malignancies. Oncol Res 1996;8:17-25.

25 Holden JA, Perkins SL, Snow GW, Kjeldsberg CR. Immunohistochemical staining for DNA topoisomerase II in non-Hodgkin's lymphomas. Am 7 Clin Pathol 1995;104: in non-

26 Martinchick JC, Rahn MP, Jolles CJ, Holden JA. DNA topoisomerase II-alpha: immunohistochemical staining foro enzyme protein in tumours of ovarian origin. Int 7 Oncol $\mathbb{Q}$ 1997;10:1229-34.

27 Duguet M, Lavenot C, Harper F, Mirambeau G, De $\overline{\bar{O}}$ Recondo AM. DNA topoisomerases from rat liver: 3 physiological variations. Nucleic Acids Res 1983;11:105974 .

28 Heck MMS, Hittelman WN, Earnshaw WC. DifferentialO expression of DNA topoisomerases I and II during the eukaryotic cell cycle. Proc Natl Acad Sci USA 1988;85:3 1086-90.

29 Baker SD, Wadkins RM, Stewart CF, Beck WT, Danks MK. Cell cycle analysis of amount and distribution of nuclear DNA topoisomerase I as determined by fluorescence? digital imaging microscopy. Cytometry 1995;19:134-45.

30 Florell SR, Martinchick JF, Holden JA. Purification of DNA topoisomerase I from the spleen of a patient witho non-Hodgkin's lymphoma. Anticancer Res 1996;16:3467-ב

73.
31 Panayotis P, Kozielski AJ, Mendoza JT, Early JA, Hinz H, 을 Giovanella BC. Camptothecin derivatives induce regression of human ovarian carcinomas grown in nude mice and distinguish between non-tumourigenic and tumourigenic cells in vitro. Int $\mathcal{F}$ Cancer 1993;53:863-71.

32 van der Zee AGJ, de Jong S, Keith WN, Hollema H, Boonstra $\mathrm{H}$, de Vries EGE. Quantitative and qualitative aspects $\omega$ of topoisomerase I and II-alpha and -beta in untreated andO platinum/cyclophosphamide treated malignant ovarian tumours. Cancer Res 1994;54:749-55.

33 Bauman ME, Holden JA, Brown KA, Harker WG, Perkins SL. Differential immunohistochemical staining for DNA topoisomerase II-alpha and -beta in human tissues and for DNA topoisomerase II-beta in non-Hodgkin's lymphomas. Mod Pathol 1997;10:168-75.

34 Hwong C, Chen C, Shang H, Hwang J. Increased synthesis and degradation of DNA topoisomerase I during the initial phase of human $\mathrm{T}$ lymphocyte proliferation. $\mathcal{F}$ Biol Chem phase of human T

35 Mcleod HL, Keith WN. Variation in topoisomerase I gene copy number as a mechanism for intrinsic drug sensitivity. Br f Cancer 1996;74:509-12.

36 Bruno S, Giaretti W, Darzynkiewicz Z. Effect of camp tothecin on mitogenic stimulation of human lymphocytes involvement of DNA topoisomerase $\mathrm{I}$ in cell transition from $\mathrm{G}_{0}$ to $\mathrm{G}_{1}$ phase of the cell cycle and in DNA replica-? tion. $\mathcal{f}$ Cell Physiol 1992;151:478-86.

37 Lynch BJ, Guinee DG, Holden JA. Human DNA topoisomerase II-alpha: a new marker of cell proliferation in invasive breast cancer. Hum Pathol. [In press.]

38 Uemura T, Ohkura H, Adachi Y, Morino K, Shiozaki K Yanagida $M$. DNA topoisomerase II is required for condensation and separation of mitotic chromosomes in $\mathrm{S}$ pombe. Cell 1987;50:917-25. 
39 Holm C, Stearns T, Botstein D. DNA topoisomerase II must act at mitosis to prevent nondisjunction and chromosome breakage. Mol Cell Biol 1989;9:159-68.

40 Charron M, Hancock R. DNA topoisomerase II is required for formation of mitotic chromosomes in chinese hamster ovary cells: studies using the inhibitor 4'demethylepipodophyllotoxin 9-(4, 6-O-thenylidene- $\beta$-D glucopyranoside). Biochemistry 1990;29:9531-7.

41 Castano IB, Heath-Pagliuso S, Sadoff BU, Fitzburgh DJ, Christman MF. A novel family of TRF (DNA topoisomerChristman MF. A novel family of TRF (DNA topoisomer-
ase I-related function) genes required for proper nuclear segregation. Nucleic Acids Res 1996;24:2404-10.
42 Muller MT, Pfund WP, Mehta VB, Trask DK. Eukaryotic type I topoisomerase is enriched in the nucleolus and catalytically active on ribosomal DNA. EMBO F 1985;4:123743.

43 Buckwalter CA, Lin AH, Tanizawa A, Pommier YG, Cheng YC, Kaufmann SH. RNA synthesis inhibitors alter the subnuclear distribution of DNA topoisomerase I. Cancer Res 1996;56:1674-81.

44 Danks MK, Garrett KE, Marion RC, Whipple DO. Subcellular redistribution of DNA topoisomerase I in anaplastic astrocytoma cells treated with topotecan. Cancer Res 1996; 56:1664-73 